\title{
Surface ligand removal in atomic layer deposition of GaN using triethylgallium
}

Cite as: J. Vac. Sci. Technol. A 39, 012411 (2021); https://doi.org/10.1116/6.0000752

Submitted: 03 November 2020 . Accepted: 10 December 2020 . Published Online: 04 January 2021

(D) Petro Deminskyi, (D) Chih-Wei Hsu, (D) Babak Bakhit, (D) Polla Rouf, and (D) Henrik Pedersen

\section{COLLECTIONS}

Paper published as part of the special topic on Atomic Layer Deposition (ALD)
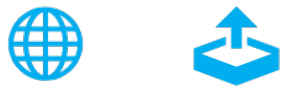

\section{ARTICLES YOU MAY BE INTERESTED IN}

Area-selective atomic layer deposition enabled by competitive adsorption

Journal of Vacuum Science \& Technology A 38, 062411 (2020); https://

doi.org/10.1116/6.0000497

Status and prospects of plasma-assisted atomic layer deposition

Journal of Vacuum Science \& Technology A 37, 030902 (2019); https://

doi.org/10.1116/1.5088582

Conformality in atomic layer deposition: Current status overview of analysis and modelling Applied Physics Reviews 6, 021302 (2019); https://doi.org/10.1063/1.5060967

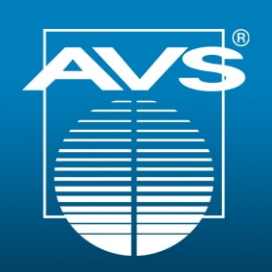

\section{Advance your science-and} career as a member of

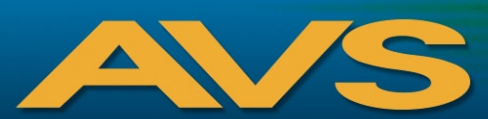

\section{LEARN MORE}




\title{
Surface ligand removal in atomic layer deposition of GaN using triethylgallium
}

Cite as: J. Vac. Sci. Technol. A 39, 012411 (2021); doi: 10.1116/6.0000752

Submitted: 3 November 2020 . Accepted: 10 December 2020 .

Published Online: 4 January 2021

Petro Deminskyi, (D) Chih-Wei Hsu, (D) Babak Bakhit, (iD Polla Rouf, (D) and Henrik Pedersen ${ }^{\text {a) (D) }}$

\section{AFFILIATIONS}

Department of Physics, Chemistry and Biology, Linköping University, SE-58183 Linköping, Sweden

Note: This paper is part of the 2021 Special Topic Collection on Atomic Layer Deposition (ALD).

${ }^{a)}$ Electronic mail: henrik.pedersen@liu.se

\begin{abstract}
Gallium nitride $(\mathrm{GaN})$ is one of the most important semiconductor materials in modern electronics. While GaN films are routinely deposited by chemical vapor deposition at around $1000^{\circ} \mathrm{C}$, low-temperature routes for $\mathrm{GaN}$ deposition need to be better understood. Herein, we present an atomic layer deposition (ALD) process for GaN-based on triethyl gallium (TEG) and ammonia plasma and show that the process can be improved by adding a reactive pulse, a "B-pulse" between the TEG and ammonia plasma, making it an ABC-type pulsed process. We show that the material quality of the deposited GaN is not affected by the B-pulse, but that the film growth per ALD cycle increases when a B-pulse is added. We suggest that this can be explained by the removal of ethyl ligands from the surface by the B-pulse, enabling a more efficient nitridation by the ammonia plasma. We show that the B-pulsing can be used to enable GaN deposition with a thermal ammonia pulse, albeit of $\mathrm{x}$-ray amorphous films.
\end{abstract}

Published under license by AVS. https://doi.org/10.1116/6.0000752

\section{INTRODUCTION}

Gallium nitride $(\mathrm{GaN})$ is a group 13-nitride semiconductor of high importance to modern electronic devices due to its optical and electronic properties. GaN has a direct and wide bandgap of $3.4 \mathrm{eV}$, a high breakdown field of $5 \mathrm{MV} \mathrm{cm}^{-1}$, high electron mobility (theoretical limit $3200 \mathrm{~cm}^{2} / \mathrm{V} \mathrm{s}$ ), high electron saturation velocity (theoretical limit $3.15 \times 10^{7} \mathrm{~cm} / \mathrm{s}$ ), and high thermal stability (melting point of $2500^{\circ} \mathrm{C}$ ) ${ }^{1,2}$ These properties make GaN important for high power and high-frequency electronics and optoelectronics. The fabrication of any electronic device requires the deposition of the material as a thin film. GaN thin films are typically deposited by chemical vapor deposition (CVD) at $800-1000^{\circ} \mathrm{C}$ using trimethylgallium, $\mathrm{Ga}\left(\mathrm{CH}_{3}\right)_{3}$ (TMG), and ammonia, $\mathrm{NH}_{3}$, as precursors. ${ }^{3}$ The high deposition temperatures and poor conformity of the established CVD processes for GaN are problematic for any device structure not compatible with high temperatures or that require uniform film thickness over topographically complex geometries. The deposition method of choice for such structures is atomic layer deposition (ALD). ALD processes for GaN have been developed, mainly using TMG as Ga precursor and $\mathrm{N}_{2} / \mathrm{H}_{2}$ or $\mathrm{NH}_{3}$ plasma as $\mathrm{N}$ precursors. ${ }^{1,4-6}$ A problem with most reported ALD process for $\mathrm{GaN}$ is a high amount of carbon contamination, on the order of several atomic percent. ${ }^{7}$ The carbon emanates from the TMG precursor, most likely due to insufficient removal of methyl groups from the surface due to the lower temperatures in ALD, $200-400^{\circ} \mathrm{C}$, compared to CVD. One route to circumvent this problem is to use $\mathrm{Ga}$ precursors with $\mathrm{Ga}-\mathrm{N}$ bonds instead of $\mathrm{Ga}-\mathrm{C}$ bonds, such as $\mathrm{Ga}\left[\mathrm{N}\left(\mathrm{CH}_{3}\right)_{2}\right]_{3}$ which has been shown as a promising alternative for ALD of $\mathrm{GaN}$. $^{8}$ Another route is to slightly modify the TMG molecule to allow for easier removal of the alkyl ligands. In contrast to TMG, triethylgallium, $\mathrm{Ga}\left(\mathrm{C}_{2} \mathrm{H}_{5}\right)_{3}$ (TEG), can undergo $\beta$-hydrogen elimination, a well-known, low-energy path for alkyl ligand removal. While ALD of GaN using TEG as a Ga precursor has been reported, the ligand abstraction enabled by the $\mathrm{C}-\mathrm{C}$ bonds in the ligands has not been fully explored. Here, we explore how the elimination of the ethyl ligands can be enhanced for a more efficient deposition process.

\section{EXPERIMENTAL DETAILS}

\section{A. Film deposition}

Depositions were carried out in a Picosun R-200 atomic layer deposition tool without a load lock chamber and a operating pressure of $6 \mathrm{hPa}$. An ICP plasma was generated within a quartz tube 
surrounded by a cylindrical RF coil with the substrate holder located approximately $70 \mathrm{~cm}$ downstream from the plasma source. ALD of GaN was done within the temperature range of $160-350{ }^{\circ} \mathrm{C}$ on $2 \times 2 \mathrm{~cm} \mathrm{Si}(100)$ with native oxide using alternative pulses of TEG and $\mathrm{NH}_{3} /$ Ar plasma, separated by $\mathrm{N}_{2}$ purges, as precursors. TEG was kept in a stainless-steel bubbler at room temperature. $\mathrm{N}_{2}$ (99.999\%) was used as a purge gas for the whole deposition system and as a carrier gas for triethylgallium precursor delivery into the reaction chamber, while $\operatorname{Ar}(99.9997 \%)$ was used as the carrier gas for $\mathrm{H}_{2}(99.999 \%)$ and $\mathrm{NH}_{3}(99.999990 \%)$ precursor delivery. The $\mathrm{N}_{2}, \mathrm{Ar}, \mathrm{NH}_{3}$, and $\mathrm{H}_{2}$ gases were further purified by getter filters to further remove moisture.

Si (100) substrates were loaded and kept at a deposition temperature for at least $120 \mathrm{~min}$ before the growth process was started. To minimize the negative impact of atmospheric exposure during the sample loading process and to remove any water vapor adsorbed from the reactor walls upon sample loading, a 2 min $\mathrm{NH}_{3} / \mathrm{Ar}$ (50/100 SCCM) $2800 \mathrm{~W}$ and $2 \mathrm{~min} \mathrm{~N}_{2} / \mathrm{Ar}$ (50/100 SCCM) $2800 \mathrm{~W}$ plasma cleaning procedure was employed. This plasma pretreatment aims to reduce oxide and carbon residuals as previously reported.

To study how to enhance the ethyl ligand removal from the surface, an additional pulse was added between the TEG and $\mathrm{NH}_{3} / \mathrm{Ar}$ plasma. This made the ALD process into an ABC-type pulsed ALD process with TEG as A-pulse, the additional gas as the B-pulse and the $\mathrm{NH}_{3} / \mathrm{Ar}$ plasma as C-pulse, similar to a previous study on ALD of aluminum nitride. ${ }^{10}$ For each set of experiments, the A-pulse was $0.3 \mathrm{~s}$ TEG exposure and the C-pulse was a $30 \mathrm{~s}$ $\mathrm{NH}_{3}$ plasma exposure using a mixture of $50 \mathrm{SCCM} \mathrm{NH}_{3}$ and 100 SCCM Ar with $2800 \mathrm{~W}$ plasma power. The $\mathrm{N}_{2}$ purge was $10 \mathrm{~s}$ after the TEG and $6 \mathrm{~s}$ after the $\mathrm{NH}_{3}$ plasma. In ABC-pulsed experiments, a 12 s B-pulse of either Ar-plasma (100 SCCM with $2000 \mathrm{~W}$ plasma power), $\mathrm{H}_{2}$ gas (50 SCCM $\mathrm{H}_{2}$ mixed with 100 SCCM Ar), or $\mathrm{H}_{2}$ plasma (50 SCCM $\mathrm{H}_{2}$ mixed with 100 SCCM Ar and $2000 \mathrm{~W}$ plasma power) was added. A $2 \mathrm{~s}_{2}$ purge was added after the B-pulse. Also, experiments were carried out using identical growth conditions except that the plasma during the $\mathrm{NH}_{3}$ step was turned off to study a thermal $\mathrm{NH}_{3}$ pulse.

\section{B. Film characterization}

The structural properties of the deposited GaN films were first analyzed by grazing incidence $x$-ray diffraction (GIXRD). A parallel beam $\mathrm{X}$-ray mirror for $\mathrm{Cu}$ radiation was used as an incident beam optics, while parallel plate collimator $0.27^{\circ}$ was used as the diffracted beam optics. The incoming beam angle, $\omega$, was $0.5^{\circ}$. Data were obtained within the $2 \theta$ range of $20^{\circ}-90^{\circ}$, which were performed using $0.05^{\circ}$ step size and $5 \mathrm{~s}$ step time. Thickness and film density of the deposited films were measured by X-ray reflectometry (XRR). GIXRD and XRR were measured with a PanAnalytical X'Pert Pro. Growth per cycle (GPC) values were calculated by dividing film thicknesses by the number of ALD cycles. Surface morphologies of the GaN films were studied using a highresolution LEO 1550 Gemini field emission scanning electron microscope (SEM). An atomic force microscope (VEECO, AFD Dimension 3100) operated under the tapping mode was used for surface topography and surface roughness. The root mean square
(RMS) surface roughness values was obtained by using the software of NANOSCOPE 5.0 to analyze the recorded results from the AFM measurements. The elemental compositions of the films were obtained using Rutherford backscattering spectrometry (RBS) and time-of-flight elastic recoil detection analyses (ToF-ERDA). The measurements were carried out in a 5 -MV NEC-5SDH-2 pelletron tandem accelerator. $2 \mathrm{MeV}^{4} \mathrm{He}^{+}$ions were employed for RBS and detected at a scattering angle of $170^{\circ}$. Two different geometries, azimuth angle $5^{\circ}+$ tilt angle $2^{\circ}$ and azimuth angle $40^{\circ}+$ tilt angle $2^{\circ}$, were chosen to minimize channeling effects. In addition, more suppression of the probable channeling effects was undertaken by multiple small random-angular movements around the equilibrium angles within a range of $2^{\circ}$. RBS spectra were fitted by SIMNRA 7.02 code. ${ }^{11}$ Recoils, in ToF-ERDA, were detected at $45^{\circ}$ angle between the primary beam and a ToF-E detector telescope in a gas ionization chamber (GIC) using a $36 \mathrm{MeV}^{127} \mathrm{I}^{8+}$ beam incident at $67.5^{\circ}$ with respect to the sample surface normal. The ToF-E detector telescope consisted of two circular carbon foils with 8 and $5 \mu \mathrm{g} / \mathrm{cm}^{2}$ thicknesses, $6 \mathrm{~mm}$ radius, a $0.05-\mathrm{msr}$ solid angle $(\Delta \Omega)$, and a flight distance of $425 \mathrm{~mm}$ between the foils. Utilizing a ToF-GIC setup provides the system with a good energy resolution and enhanced ion species separation in terms of mass and energy. ${ }^{12}$ Average elemental compositions were also obtained from ToF-ERDA timeenergy coincidence spectra using two different software packages, CONTES $^{13}$ and Potku. ${ }^{14}$ Systematic uncertainties of the experiment, discussed in more detail elsewhere ${ }^{15}$ for light elements, were estimated to be a maximum of $5 \%-10 \%$, whereas statistic uncertainties arisen from the number of experimental counts were $\leq 1.7 \%$. However, the relative elemental concentrations were obtained with higher accuracy. ${ }^{16,17}$ The stopping power data required for both RBS and ERDA simulations were retrieved from SRIM2013 code. ${ }^{18}$ Chemical composition and bonding states of the films were determined by an Axis Ultra DLD instrument from Kratos Analytical x-ray photoelectron spectroscopy (XPS) with a base pressure of $1.1 \times 10^{-9}$ Torr $\left(1.5 \times 10^{-7} \mathrm{~Pa}\right)$ and monochromatic Al Ka source $(h v=1486.6 \mathrm{eV})$. Depth profiling was carried out using an Ar ion sputter beam with an acceleration voltage, spot size, and sputtering time duration of $0.5 \mathrm{kV}, 300 \times 700 \mu \mathrm{m}$, and $300 \mathrm{~s}$, respectively. Spectra deconvolution and quantification were performed using CASA XPS software. During the peaks fitting, the C $1 \mathrm{~s}$ peak at $285 \mathrm{eV}$ was taken as a reference for all charge shift corrections.

\section{RESULTS}

By depositing films between 160 and $350{ }^{\circ} \mathrm{C}$, using $0.3 \mathrm{~s}$ of TEG pulse, it is found that the deposition process is stable at temperatures upto, within experimental error, around $320^{\circ} \mathrm{C}$ [Fig. 1(a)]. The temperature stability is regardless of which B-pulse is used, albeit the different B-pulses render different GPC. GaN deposited at $320^{\circ} \mathrm{C}$ was then chosen as the deposition temperature to study the variation of GPC with TEG pulse time. The film deposition process shows a saturating behavior for TEG pulses $\geq 0.3 \mathrm{~s}$, regardless of which B-pulse was used, and again the GPC values were different for the different B-pulses [Fig. 1(b)]. For both the temperature and the TEG pulse length studies, adding a B-pulse affords a higher GPC. $\mathrm{H}_{2}$ plasma as B-pulse affords the highest 

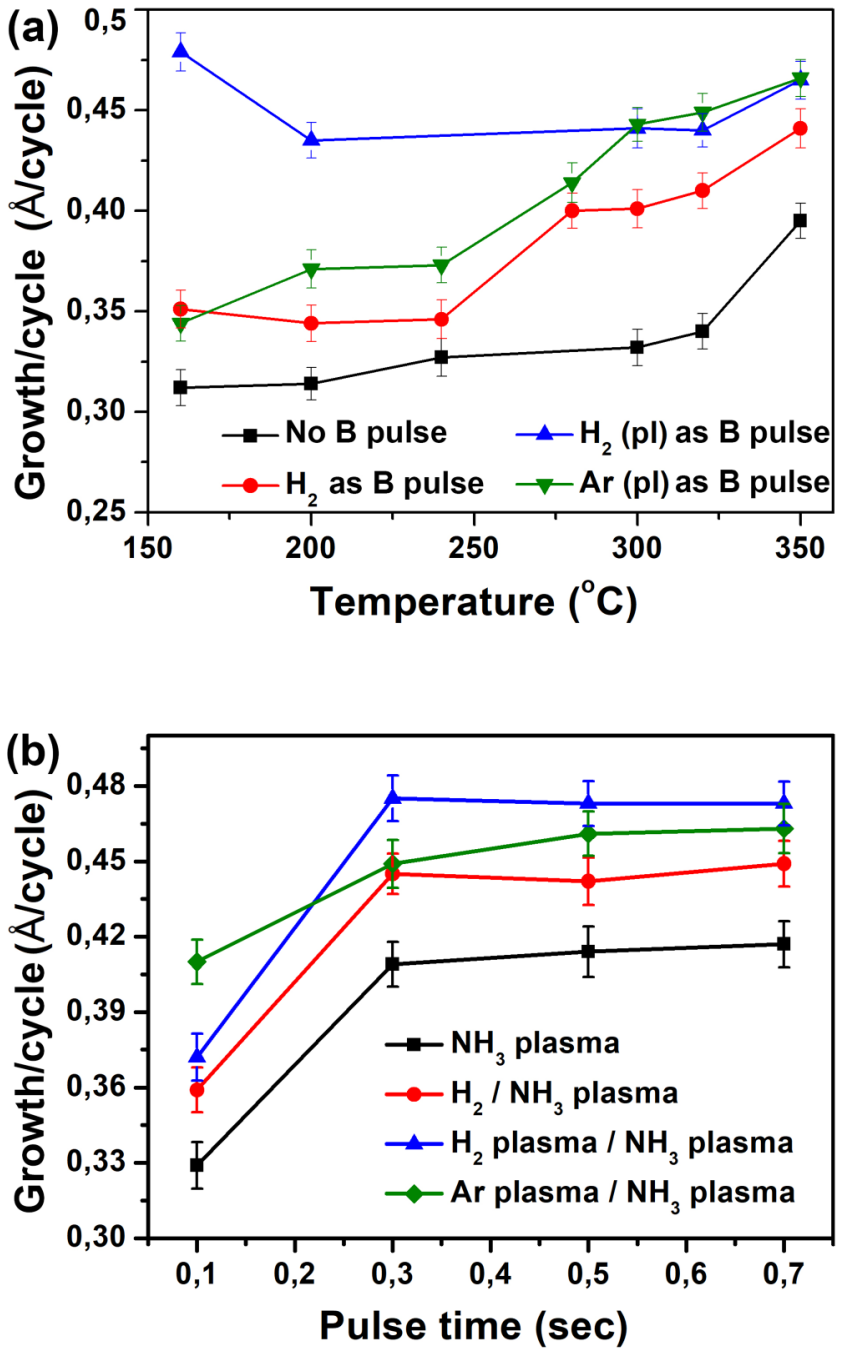

FIG. 1. Growth per cycle (GPC) for film deposition at different temperatures (a) and with different TEG pulse time (b).

GPC, Ar plasma a somewhat lower GPC, and $\mathrm{H}_{2}$ gas shows the lowest increase in GPC. Without B-pulse, the GPC seems independent of temperature [Fig. 1(a)] between 160 and $320^{\circ} \mathrm{C}$. The GPC saturates at $0.41 \AA /$ cycle for the TEG pulse $\geq 0.3 \mathrm{~s}$ [Fig. 1(b)]. Despite different GPC observed for different temperatures, the

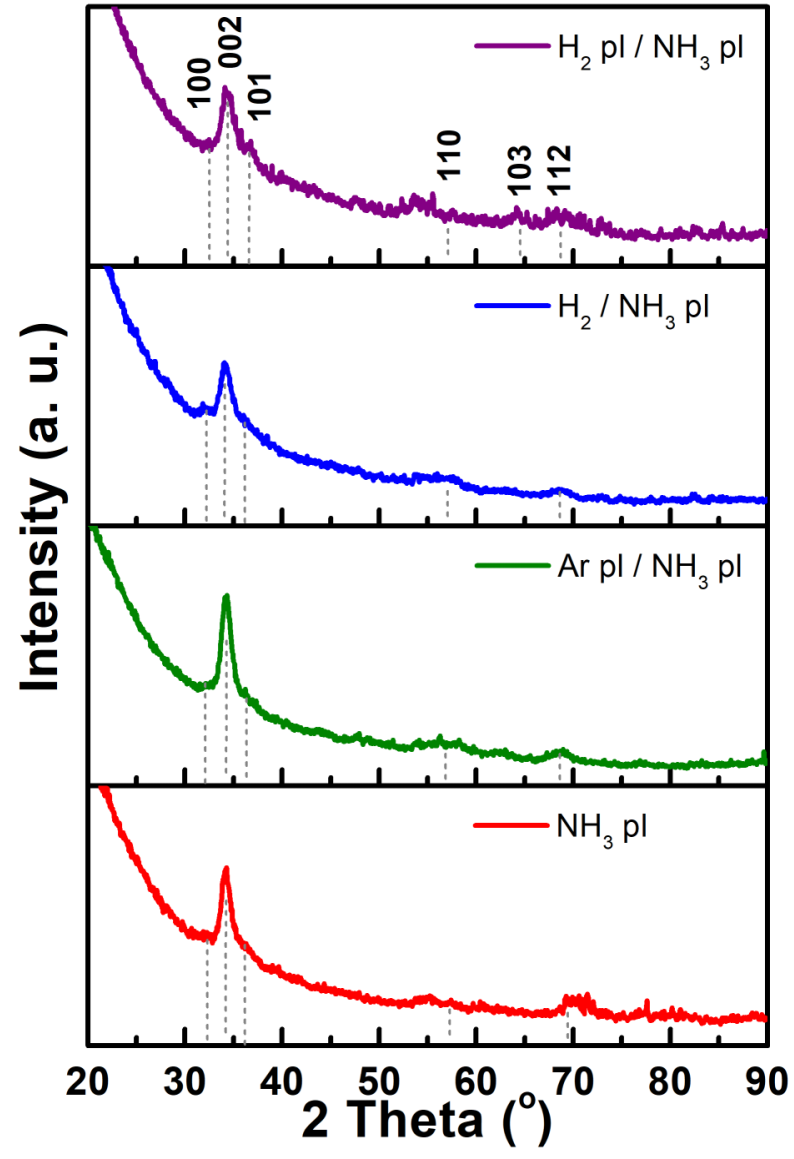

FIG. 2. GI-XRD scans of $35 \pm 3 \mathrm{~nm}$ thick films deposited at $320^{\circ} \mathrm{C}$ with different B-pulses. All diffraction peaks can be indexed to hexagonal $\mathrm{GaN}$.

impact of different B-pulses on the GPC is clear: $\mathrm{H}_{2}$ plasma $\geq \mathrm{Ar}$ plasma $>\mathrm{H}_{2}$ as can be seen in Fig. 1.

Stoichiometry and impurity levels of the films were measured by RBS and ERDA (Table I) on $35 \pm 3 \mathrm{~nm}$ thick films deposited at $320^{\circ} \mathrm{C}$. As seen in Table I, all films are $\mathrm{Ga}$ rich and have $2-3$ atomic \% oxygen impurities, explained by the oxyphilic nature of $\mathrm{GaN}$ and the exposure to air for several days prior to ERDA/RBS measurements. The carbon impurity level is around 1 at. $\%$ in the films where no B-pulse is used or if $\mathrm{H}_{2}$ gas is used as the B-pulse. When $\mathrm{H}_{2}$ plasma or Ar-plasma are used as B-pulse, the carbon

TABLE I. Elemental composition from ERDA/RBS.

\begin{tabular}{|c|c|c|c|c|c|c|}
\hline B-pulse & $\mathrm{Ga}$ (at. \%) & $\mathrm{N}$ (at. \%) & $\mathrm{Ga} / \mathrm{N}$ & C (at. \%) & O (at. \%) & $\mathrm{H}$ (at. \%) \\
\hline None & $56.5 \pm 1.4$ & $38.0 \pm 1.5$ & 1.49 & $1.0 \pm 0.4$ & $2.3 \pm 0.5$ & $2.2 \pm 0.3$ \\
\hline $\mathrm{H}_{2}$ & $54.5 \pm 1.4$ & $41.0 \pm 1.3$ & 1.33 & $1.0 \pm 0.2$ & $1.7 \pm 0.3$ & $1.8 \pm 0.2$ \\
\hline Ar-plasma & $50.2 \pm 1.3$ & $44.1 \pm 1.7$ & 1.13 & $0.3 \pm 0.1$ & $2.9 \pm 0.5$ & $2.5 \pm 0.1$ \\
\hline $\mathrm{H}_{2}$-plasma & $54.0 \pm 1.0$ & $41.4 \pm 1.2$ & 1.31 & $0.7 \pm 0.1$ & $2.3 \pm 0.3$ & $1.6 \pm 0.1$ \\
\hline
\end{tabular}



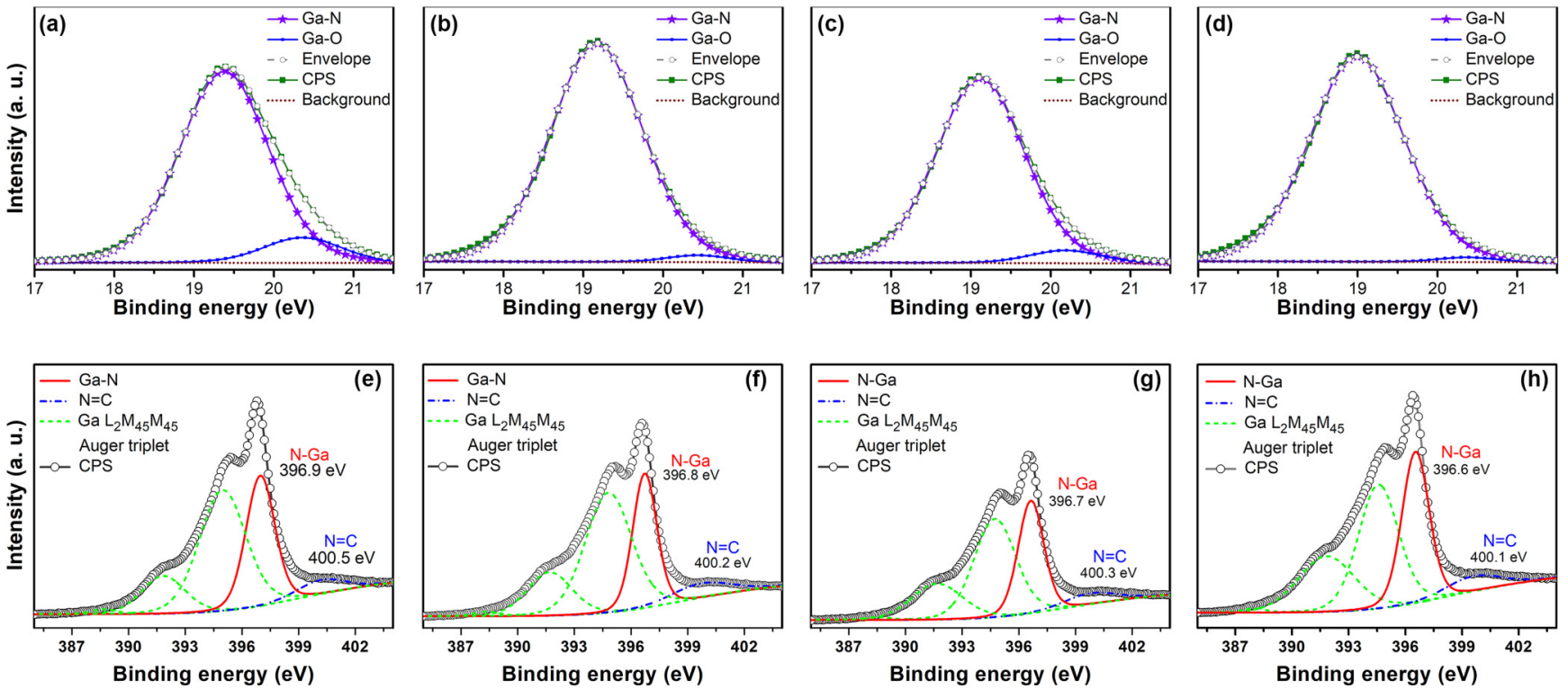

FIG. 3. HR-XPS data, Ga 3d [(a)-(d)] and N 1s [(e)-(h)] bands, of $45 \pm 5 \mathrm{~nm}$ GaN films deposited at $320^{\circ} \mathrm{C}$ with different B-pulses. No B-pulse (a) and (e); Ar-plasma as B-pulse (b) and ( $\mathrm{f}$ ); $\mathrm{H}_{2}$ gas as B-pulse (c) and (g), $\mathrm{H}_{2}$ plasma as B-pulse (d) and (h).

level decreases to 0.7 and 0.3 at. \%, respectively. The hydrogen content in the films is in the range of $1.6-2.5$ at. \%. It should also be noted that ERDA is a method that determines the absolute total hydrogen content ${ }^{19}$ and there is no information on whether the
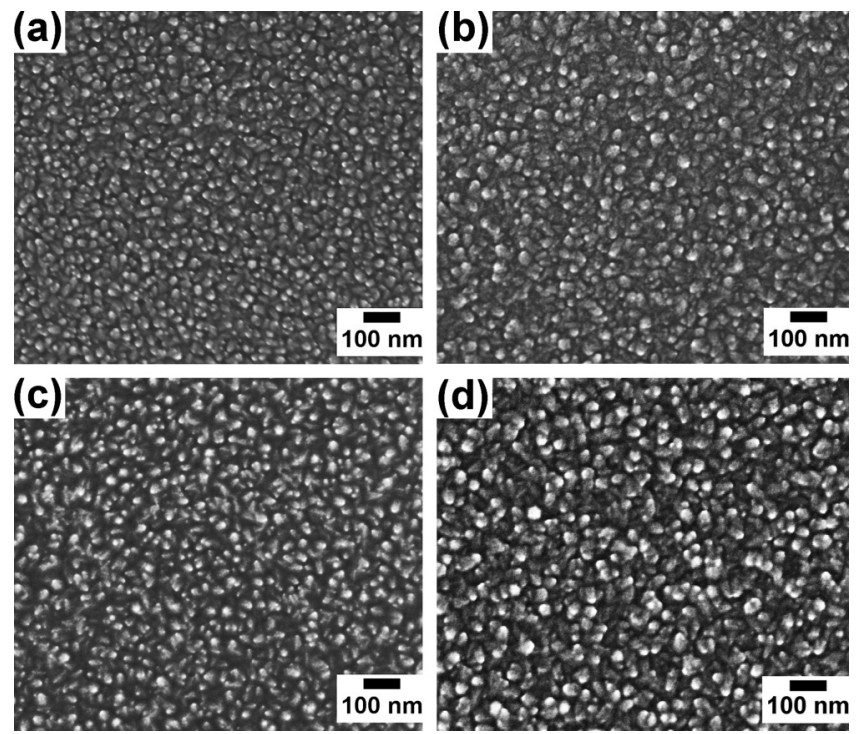

FIG. 4. Top-view scanning electron micrographs of $35 \pm 3 \mathrm{~nm}$ thick films deposited at $320^{\circ} \mathrm{C}$ with different B-pulses: no B-pulse (a), Ar-plasma as B-pulse (b), $\mathrm{H}_{2}$ gas as B-pulse (c), and $\mathrm{H}_{2}$-plasma as B-pulse (d). hydrogen in the films is bonded, unbonded, or molecular hydrogen.

The crystal structure of $35 \pm 3 \mathrm{~nm}$ thick films deposited at $320^{\circ} \mathrm{C}$ is found to be consistent with polycrystalline hexagonal GaN GIXRD (ICDD reference code: 01-073-7289) (Fig. 2). It can be noted that the B-pulse does not seem to affect the crystallinity of the films. For the ABC-type approach presented in this manuscript, the film density was found to be $5.4 \mathrm{~g} / \mathrm{cm}^{3}$ (no B-pulse), $5.0 \mathrm{~g} / \mathrm{cm}^{3}$ (Ar-plasma as B-pulse), $4.9 \mathrm{~g} / \mathrm{cm}^{3}\left(\mathrm{H}_{2}\right.$-gas as B-pulse), and $5.6 \mathrm{~g} / \mathrm{cm}^{3}\left(\mathrm{H}_{2}\right.$-plasma as B-pulse) which should be compared to $6.15 \mathrm{~g} / \mathrm{cm}^{3}$ for bulk GaN. Thus, the B-pulse has a slight effect on the film density.

Figure 3 shows the high-resolution XPS scans of the Ga 3d and $\mathrm{N} 1 \mathrm{~s}$ spectral regions of GaN with $40-51 \mathrm{~nm}$ thick films deposited at $320^{\circ} \mathrm{C}$ with different B-pulses. The $\mathrm{Ga} 3 \mathrm{~d}$ spectral region [Figs. 3(a)-3(d)] is dominated by a peak at $18.9 \pm 0.5 \mathrm{eV}$, corresponding to $\mathrm{Ga}-\mathrm{N}$ bonding. ${ }^{5}$ A minor shoulder peak at $20.5 \pm 0.5 \mathrm{eV}$ corresponding to Ga-O bonding. ${ }^{20}$ The N 1s XPS spectral region shows a dominant peak at $396.6 \pm 0.3 \mathrm{eV}$, corresponding to $\mathrm{N}-\mathrm{Ga}$ bonds ${ }^{8}$ with a shoulder peak at $400.1 \pm 0.4 \mathrm{eV}$, corresponding to $\mathrm{N}=\mathrm{C}$ bonding. ${ }^{21}$ Auger peaks from the $\mathrm{Ga}$ region are also observed in the $\mathrm{N} 1 \mathrm{~s}$ spectral region. It can be noted from Figs. 4(a)-4(e) that the B-pulse seems to reduce the Ga-O bonds in the films.

Top view scanning electron micrographs (Fig. 4) show that the $35 \pm 3 \mathrm{~nm}$ thick films deposited at $320^{\circ} \mathrm{C}$ with different B-pulses have very similar morphology. According to the surface roughness analysis in our AFM measurements, the root mean square (RMS) surface roughness values were found to be $0.8 \mathrm{~nm}$ without B-pulse, $1.4 \mathrm{~nm}$ with Ar-plasma as B-pulse, $1.0 \mathrm{~nm}$ with $\mathrm{H}_{2}$ gas as B-pulse, and $1.1 \mathrm{~nm}$ with $\mathrm{H}_{2}$-plasma as B-pulse. 


\section{DISCUSSION}

The results presented above show that the B-pulses does not affect crystal structure, chemical bonds, or morphology of the deposited GaN films. The elemental composition of the films is only affected to a small degree by an Ar plasma as B-pulse. The most noticeable effect of the B-pulse is an increase in GPC compared to when not using a B-pulse. We hypothesize that the increase in GPC is explained by more favorable surface chemistry for the nitridation step in the deposition: After the TEG pulse, the surface will be saturated by $\mathrm{Ga}$ atoms bearing one or two ethyl ligands. If no B-pulse is used, the elimination of these ethyl ligands is done by the $\mathrm{NH}_{3}$ plasma pulse which also nitridize the surface. If a B-pulse is used, the B-pulse could induce chemistry that eliminates the ethyl ligands from the surface, replacing them with other surface species that are easier to remove during the nitridation.

The gas-phase decomposition pathways of TEG at CVD conditions for deposition of gallium phosphide, $400-675^{\circ} \mathrm{C}$ and $5000 \mathrm{~Pa}$, has previously been studied by quantum chemical calculations. ${ }^{22}$ It was then found that TEG has two decomposition pathways in the gas phase: $\beta$-hydrogen elimination of $\mathrm{C}_{2} \mathrm{H}_{4}$ and $\mathrm{H}_{2}$ assisted elimination of $\mathrm{C}_{2} \mathrm{H}_{6}$. Both pathways eliminates one ethyl ligand and replaces it with a hydrogen atom on the gallium atom. The $\beta$-hydrogen elimination of the first ethyl ligand is thermodynamically favored at $400^{\circ} \mathrm{C}$, while further $\beta$-hydrogen eliminations of the other two ethyl ligands are not favored at $400{ }^{\circ} \mathrm{C}$, but are favored at $500{ }^{\circ} \mathrm{C}$. The $\mathrm{H}_{2}$ assisted elimination of $\mathrm{C}_{2} \mathrm{H}_{6}$ is thermodynamically favored for all three ethyl ligands already at $400{ }^{\circ} \mathrm{C}$.

Given these chemical pathways for the gas-phase decomposition of TEG, the B-pulses used in this study could induce ethyl eliminating surface chemistries: $\mathrm{H}_{2}$ gas as B-pulse would favor $\mathrm{H}_{2}$ assisted $\mathrm{C}_{2} \mathrm{H}_{6}$ elimination, an Ar-plasma would bring additional energy to the surface favoring $\beta$-hydrogen eliminations, and an $\mathrm{H}_{2}$-plasma as B-pulse would favor both $\mathrm{H}_{2}$ assisted $\mathrm{C}_{2} \mathrm{H}_{6}$ elimination and $\beta$-hydrogen elimination of $\mathrm{C}_{2} \mathrm{H}_{4}$ as it brings both energy and hydrogen to the surface. These suggested surface chemical paths, summarized in Fig. 5, would all render a hydrogen-terminated surface.

The variation in GPC with the different B-pulses presented in (Fig. 1) shows that the GPC increases as: no B-pulse $<\mathrm{H}_{2}$ gas $<$ Ar-plasma $<\mathrm{H}_{2}$-plasma. It can also be seen that the most significant increase is between no B-pulse and $\mathrm{H}_{2}$ gas as B-pulse, while the

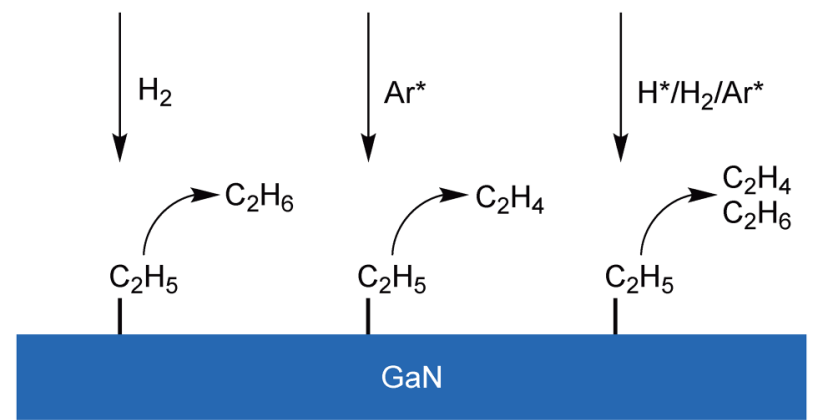

FIG. 5. Summary of the suggested mechanisms for the enhanced removal of surface ethyl groups induced by the different B-pulses.
B-pulses bring, within experimental errors, almost the same improvement in GPC. We propose that the B-pulse serves to eliminate ethyl ligands from the surface, enabling a larger fraction of the surface to be nitridized by the $\mathrm{NH}_{3}$ plasma since the nitridation will then to a larger extend be done on a hydrogen-terminated surface:

$$
\begin{gathered}
\vdash \mathrm{Ga}-\left(\mathrm{C}_{2} \mathrm{H}_{5}\right)_{x} \stackrel{\mathrm{NH}_{3}-\text { plasma }}{\longrightarrow} \vdash \mathrm{Ga}-\mathrm{NH}_{\mathrm{x}} \\
\vdash \mathrm{Ga}-\left(\mathrm{C}_{2} \mathrm{H}_{5}\right)_{x} \stackrel{B-\text { pulse }}{\longrightarrow} \vdash \mathrm{Ga}-\mathrm{H} \stackrel{\mathrm{NH}_{3}-\text { plasma }}{\longrightarrow} \vdash \mathrm{Ga}-\mathrm{NH}_{x}
\end{gathered}
$$

From the elemental composition of the films (Table I), adding a B-pulse renders a $\mathrm{Ga} / \mathrm{N}$-ratio closer to unity since the nitrogen content of the film increases. This could be an indication of more favored surface chemistry for the nitridation process with the B-pulse, which supports the above reasoning. We note that Ar-plasma as B-pulse gives the $\mathrm{Ga} / \mathrm{N}$ ratio closest to 1 . We speculate that this B-pulse should have the least reduction power which means that $\mathrm{Ga}(\mathrm{III})$ should have the lowest probability to be reduced to $\mathrm{Ga}$ (I) or $\mathrm{Ga}(0)$ with Ar-plasma. Since a $\mathrm{NH}_{3}$-plasma has very little oxidizing power for the formation of $\mathrm{Ga}$ (III)-nitride from $\mathrm{Ga}$ (I) or $\mathrm{Ga}$ (0) surface species. Such a reduction of Ga would be detrimental to the GaN and could lead to a Ga-rich stoichiometry. It should be noted that the carbon content of the films is not significantly affected by the $\mathrm{B}$-pulses which indicate that the $\mathrm{NH}_{3}$-plasma can eliminate the ethyl ligands and that the B-pulse acts to prepare the surface, presumably via the formation of more reactive or less sterically hindered intermediate(s) for subsequent nitridation. However, we note that using a $\mathrm{Ga}$ precursor with $\mathrm{Ga}-\mathrm{N}$ bonds seems to be a more favourable route to $\mathrm{GaN}$ with a $\mathrm{Ga} / \mathrm{N}$ ratio closer to 1 , as we showed in a recent publication using $\mathrm{Ga}_{2}\left(\mathrm{~N}\left(\mathrm{CH}_{3}\right)_{2}\right)_{6}{ }^{8}$

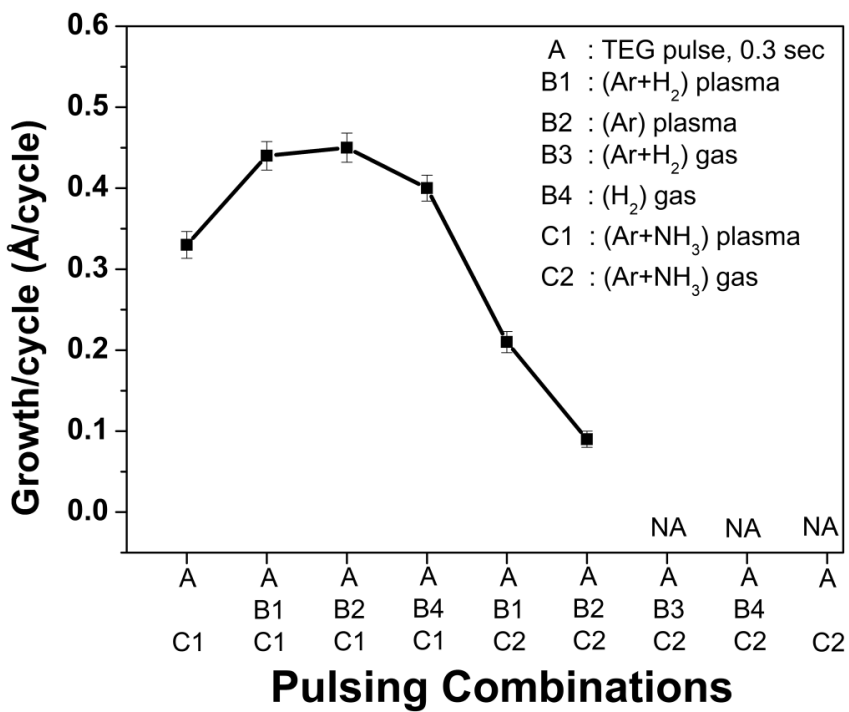

FIG. 6. Summary of the GPCs measured for the different ALD processes in this study. 


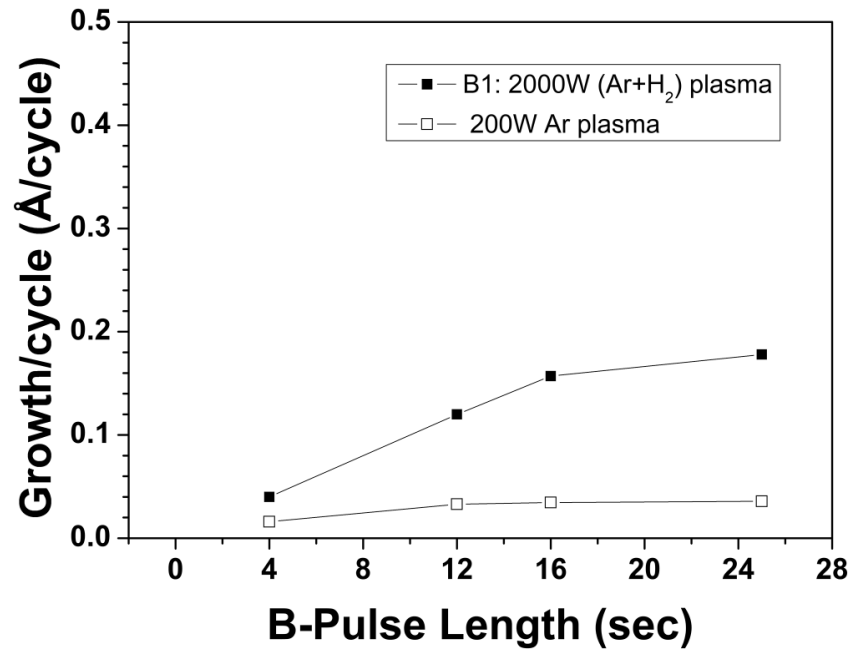

FIG. 7. Growth per cycle for different time of the B-pulse when a thermal $\mathrm{NH}_{3}$ pulse is used.

Finally, ALD runs with a thermal ammonia step were conducted to study if the B-pulses render surface reactivity towards thermal $\mathrm{NH}_{3}$. B-pulses without plasma and no B-pulse, i.e., an all-thermal ALD process with TEG and $\mathrm{NH}_{3}$ rendered no film. Both Ar- and $\mathrm{H}_{2}$-plasma as B-pulse lead to deposition of a film with a thermal $\mathrm{NH}_{3}$ pulse, where the GPC was higher for the $\mathrm{H}_{2}$-plasma, $0.2 \AA /$ cycle, and $0.1 \AA /$ cycle, respectively. These films were found to be $\mathrm{x}$-ray amorphous and have much lower GPC compared to those made using $\mathrm{NH}_{3}$ plasma. All GPCs obtained in this study are summarized in Fig. 6. ERDA analysis of these films showed very high oxygen content (57-75 at. \%), low gallium content (12-38 at. \%), and almost no nitrogen (1-5 at. \%). We assign this to severe postdeposition oxidation, the films were stored in the air several days prior to ERDA analysis and interpret these contents as an indication of the very poor quality of the films.

We note that the GPC of the GaN film show a saturative behavior with the length of the B-pulse in these experments with a thermal $\mathrm{NH}_{3}$ pulse (Fig. 7). We have not studied saturation of the GPC with the B-pulse length for $\mathrm{NH}_{3}$ plasma as film deposition with $\mathrm{NH}_{3}$ plasma show much higher GPC than film deposition with thermal $\mathrm{NH}_{3}$ given the higher reactivity of the $\mathrm{NH}_{3}$ plasma.

\section{SUMMARY}

We show that the GPC in the ALD process for GaN from TEG and $\mathrm{NH}_{3}$-plasma can be increased by adding a reactive pulse, providing energetic species, reactive species, or both to the surface, between the TEG pulse and the $\mathrm{NH}_{3}$-plasma. The reactive pulse shows no effect on the material properties of the deposited films. We suggest that this is explained by the removal of the ethyl ligands by the reactive pulse, rendering a hydrogen-terminated surface, which is more favored for nitridation. We also show that a reactive pulse can allow for film deposition with thermal $\mathrm{NH}_{3}$, but only affords x-ray amorphous films of very low quality.

\section{ACKNOWLEDGMENTS}

This project was funded by the Swedish Foundation for Strategic Research through the project "Time-resolved lowtemperature CVD for III-nitrides" (No. SSF-RMA 15-0018) and by the Knut and Alice Wallenberg Foundation through the project "Bridging the THz gap" (No. KAW 2013.0049). P.D. acknowledges the Carl Trygger Foundation for a post-doctoral scholarship at the Linköping University.

\section{DATA AVAILABILITY}

The data that support the findings of this study are available from the corresponding author upon reasonable request.

\section{REFERENCES}

${ }^{1}$ S. Banerjee, A. A. I. Aarnink, and D. J. Gravesteijn, and A. Y. Kovalgin, J. Phys. Chem. C 123, 23214 (2019)

${ }^{2}$ K. Park, M. A. Stroscio, and C. Bayram, J. Appl. Phys. 121, 245109 (2017).

${ }^{3}$ H. Hu, B. Zhang, L. Liu, D. Xu, Y. Shao, Y. Wu, and X. Hao, Crystals 10, 141 (2020).

${ }^{4}$ C. Ozgit, I. Donmez, M. Alevli, and N. Biyikli, J. Vac. Sci. Technol. A 30, 01A124 (2012).

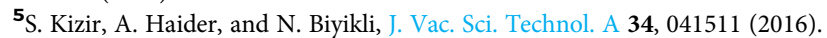

${ }^{6}$ M. Alevli, A. Haider, S. Kizir, S. A. Leghari, and N. Biyikli, J. Vac. Sci. Technol. A 34, $01 \mathrm{~A} 137$ (2016).

${ }^{7}$ S. Banerjee, A. J. Onnink, S. Dutta, A. A. I. Aarnink, D. J. Gravesteijn, and A. Y. Kovalgin, J. Phys. Chem. C 122, 29567 (2018).

${ }^{8}$ P. Rouf, N. J. O’Brien, S. C. Buttera, I. Martinovic, B. Bakhit, E. Martinsson, J. Palisaitis, C.-W. Hsu, and H. Pedersen, J. Mater. Chem. C 8, 8457 (2020).

${ }^{9}$ J. H. Kim, H. G. Choi, M.-W. Ha, H. J. Song, C. H. Roh, J. H. Lee, J. H. Park, and C.-K. Hahn, Jpn. J. Appl. Phys. 49, 04DF05 (2010).

${ }^{10}$ P. Rouf, P. Sukkaew, L. Ojamäe, and H. Pederen, J. Phys. Chem. C 124, 14176 (2020).

${ }^{11}$ M. Mayer, W. Eckstein, H. Langhuth, F. Schiettekatte, and U. Von Toussaint, Nucl. Instrum. Methods Phys. Res., Sect. B 269, 3006 (2011).

${ }^{12}$ P. Ström, P. Petersson, M. Rubel, and G. Possnert, Rev. Sci. Instrum. 87, 103303 (2016).

${ }^{13}$ K. S. Janson, CONTES (Uppsala University, Sweden, 2004).

${ }^{14}$ K. Arstila, J. Julin, M. I. Laitinen, J. Aalto, T. Konu, S. Kärkkäinen, S. Rahkonen, M. Raunio, J. Itkonen, J. P. Santanen, T. Tuovinen and T. Sajavaara, Nucl. Instrum. Methods Phys. Res., Sect. B 331, 34 (2014).

${ }^{15}$ Y. Zhang, H. J. Whitlow, T. Winzell, I. F. Bubb, T. Sajavaara, K. Arstila, and J. Keinonen, Nucl. Instrum. Methods Phys. Res., Sect. B 149, 477 (1999).

${ }^{16}$ M. A. Arvizu, R. T. Wen, D. Primetzhofer, J. E. Klemberg-Sapieha, L. Martinu, G. A. Niklasson, and C. G. Granqvist, Appl. Mater. Interfaces 7, 26387 (2015).

${ }^{17}$ H. Y. Qu, D. Primetzhofer, M. A. Arvizu, Z. Qiu, U. Cindemir, C. G. Granqvist, and G. A. Niklasson, Appl. Mater. Interfaces 9, 42420 (2017).

${ }^{18}$ J. F. Ziegler, M. D. Ziegler and J. P. Biersack, Nucl. Instrum. Methods Phys. Res., Sect. B 268, 1818 (2010).

${ }^{19}$ U. Kroll, J. Meier, A. Shah, S. Mikhailov, and J. Weber, J. Appl. Phys. 80, 4971 (1996).

${ }^{20}$ P. Deminskyi, A. Haider, A. Ovsianitsky, A. Tsymbalenko, D. Kotov, V. Matkivskyi, N. Liakhova, V. Osinsky, and N. Biyikli, in IEEE 36th International Conference on Electronics and Nanotechnology (ELNANO), Kyiv 19-21 April 2016 (IEEE, Kiev, Ukraine, 2016), p. 128.

${ }^{21}$ J. T. Titantah and D. Lamoen, Diam. Relat. Mater. 16, 581 (2007).

${ }^{22}$ A. Stegmüller, P. Rosenowa, and R. Tonner, Phys. Chem. Chem. Phys. 16, 17018 (2014). 